\title{
THE EFFECT OF MODERATE AND SEVERE BURN INJURIES ON HUMAN LIVER, KIDNEY \& BLOOD (BIOCHEMICAL STUDY)
}

\author{
Samira M. Saleh* \& Mohammed H. Hassan ** and Ahmed M. Tohamy*** \\ Departments of Forensic Medicine \& Clinical Toxicology*, Medical Biochemistry and Molecular Biology** \\ Faculty of medicine South Valley University *,** department of Plastic Surgery, Faculty of medicine, Assiut \\ University ***, Egypt
}

\begin{abstract}
The current study was done to determine changes in hematological, renal and hepatic parameters induced by moderate and severe burn injuries. Patients and Methods: the study was done during the period from march 2016 to December 2016 on 60 adult patients, who were admitted at burn unit of Assiut university hospitals with burn area $\geq 20 \%$ of body surface, and 20 healthy adults considered as control. The patients and control were investigated for renal and hepatic functions, serum sodium $\left(\mathrm{Na}^{+}\right) \&$ potassium $\left(\mathrm{K}^{+}\right) \&$ and blood picture. Results: the blood urea and serum creatinine levels were significantly increased in burn patients in comparison to control, the blood glucose showed significant increase on the first day then decrease gradually on the $3^{\text {rd }}$ and $5^{\text {th }}$ days post burn. The serum $\mathrm{Na}^{+} \& \mathrm{~K}^{+}$levels decreased significantly during the $3^{\text {rd }}$ and $5^{\text {th }}$ days post burn, the blood picture showed a significant increase in white blood cells (WBCs) and Neutrophil count ratio in burn patients in comparison to control, the Platelet count showed a significant reduction in burn patients throughout the whole period of the study while hemoglobin $(\mathrm{Hb})$ level showed significant lowering during the $3^{\text {rd }}$ and $5^{\text {th }}$ days post burn, the red blood cells (RBCs) count showed a significant increased on the $1^{\text {st }}$ day, then decreased significantly on the $5^{\text {th }}$ day post burn, the hematocrit (HCT) value showed a significant decrease on the $3^{\text {rd }}$ and $5^{\text {th }}$ days post burn. Regarding the liver functions, the serum levels of liver enzymes showed a significant increase in burn patients in comparison to control, the serum protein and albumin showed a significant decrease in burn patients, the prothrombin concentration was reduced and Prothrombin time was prolonged significantly, while the (INR) showed a significant increase in patients in comparison to control.
\end{abstract}

Key words: hematological parameters, kidney \&liver function, serum electrolytes moderate \& severe burn

Corresponding Author: Samira M. Saleh

Assistant professor of Forensic Medicine \& Clinical Toxicology.

Faculty of Medicine, Qena.

South Vally university.Egypt.

\section{INTRODUCTION}

B urns is the fourth most common type of trauma worldwide, where $90 \%$ of burn injuries occur in low and middle income countries (Peck et al., 2013).

Thermal injuries which affect more than $20 \%$ of total body surface area induce a massive capillary leakage and autonomic disturbances (Pham et al., 2008). Also the burn injuries lead to disruption of sodiumATPase activity through cell membrane resulting in intracellular retention of sodium, osmotic shifts, and cellular edema. Aggregation of Mast cells to the burn area results in secretion of histamine, which leads to extravasation of proteins and plasma fluid from the intravascular compartment into the tissues (Cakir and Yagen , 2004), (AlMuhammadi and Azeez, 2011).

The incidence of acute renal failure in burn patients ranges from 1.3 to $38 \%$, and is associated with high mortality rates (73 to
$100 \%$ ). Early in the acute phase of burn injury, renal blood flow (RBF) and glomerular filtration rate (GFR) are decreased due to the decrease in cardiac output. This activates the rennin-angiotensin-aldosterone system and stimulates release of antidiuretic hormone. The overall effect is sodium and water retention accompanied by a great loss of potassium, calcium, and magnesium (Cakir and Yagen , 2004).

The liver plays a very important role in survival and recovery of burn patients through its inflammatory, metabolic and immune functions (Jeschke et al., 2007). Burn patients may have significant reduction in serum albumin level due to high vascular permeability in the burn area and also due to acute phase response of synthesis of plasma proteins in the liver which occurs even in a very small surface area burn $(0.8 \%)$ (Kim et al., 2003). Regarding the serum level of hepatic enzymes \{alanine transaminase 
(ALT), aspartate transaminase (AST) and alkaline phosphatase (ALP) $\}$ the researchers found that their level raised gradually and reach maximum on the $5^{\text {th }}$ day and declined on the $10^{\text {th }}$ day after burn (Halkes et al., 2002). The prothrombin time may be prolonged in the early stage after burn due to hepatic dysfunction, but it return to normal in a few weeks (Lavrentieva 2016).

Hemoconcentration is one of the earliest findings in burn injuries resulting from the loss of circulating plasma volume. However, after the initial resuscitation, patients are more often anemic due to hemodilution from fluid administration (Hettiaratchy and Papini, 2004).

Over time, suppression of erythropoietin production, blood loss from frequent debridement and other surgical procedures, and hemolysis of heat-damaged red blood cells contribute to longstanding anemia in this patient population. Autoimmune hemolytic anemia may also develop (Posluszny and Gamelli (2010).

Hypercoagulability that ensues many burn injuries may predispose the patient to disseminated intravascular coagulation and episodes of vascular occlusion. White blood cells counts (WBCs) are usually elevated following burn injuries; however, severe sepsis and silver sulfadiazine in wound dressings may cause leukopenia, therefore offsetting the leukocytosis (Hettiaratchy and Papini , 2004).

Aim of work: is to evaluate the effect of thermal injuries on liver and kidney functions, blood glucose, serum electrolytes $\left(\mathrm{Na}^{+}\right.$and $\left.\mathrm{K}^{+}\right)$and complete blood count.

\section{PATIENTS AND METHODS}

This study was a case control hospital based study conducted on 60 patients, who admitted at the burn unit of Assiut university hospitals, and were selected according to the inclusion criteria, also 20 apparently healthy age and sex matched persons selected as control group. The study was approved by the ethical committee of our institute and informed consent from the included patients and control persons was obtained, the study was carried out during the period from march the $1^{\text {st }} 2016$ to December the $30^{\text {th }} 2016$.
Inclusion criteria: male \& female Patients aging between 18 to 60 years old, with $2^{\text {nd }}$ and $3^{\text {rd }}$ degree thermal injuries including dry burn, scalds and electrical burn, with burn area $\geq 20 \%$ of total body surface area.

Exclusion criteria: Cardiac, hepatic and renal patients, diabetes mellitus, hypertension, bleeding tendencies, and chronic debilitating diseases.

\section{Methodology:}

1-Taking history from the patients to determine the etiology and the time of the burn, exclude patients below 18 and patient above 60 years, and exclude patients with chronic diseases mentioned in the exclusion criteria.

2-Clinical examination of all the included patients to determine the degree and type of burn, and surface area affected.

3-The followings biochemical parameters were measured in patient at time of admission (Burn A), then repeated at $3^{\text {rd }}$ day post burn (Burn B), and on $5^{\text {th }}$ day from admission (Burn C), they include:

-Spectrophotometric measurements of blood glucose, liver functions (ALT, AST, ALP, total proteins and albumin), kidney functions (blood urea and serum creatinine) using Cobas C311 (Roche diagnostics, Germany).

-Serum electrolytes $\left(\mathrm{Na}^{+}\right.$and $\left.\mathrm{K}^{+}\right)$, using Easylyte Medica- USA.

-Complete blood count, using Cell Dyn 1800-Abbott diagnostics- USA.

Statistical analysis: the data obtained from the patients under the study and the control persons were analyzed using statistical package for the social science (SPSS, version 22) software and presented as mean \pm SD. The blood and serum parameters of burn patients were compared with those of healthy control, and the results were considered significant when $\mathrm{p}$ value was lower than 0.05

\section{RESULTS}

The study was done over ten months, sixty patients were involved, table (1) shows burn characteristics of the studied patients were most of them (76.7\%) have got thermal burns due to flame, followed by scalds $(16.6 \%)$ and lastly the electrical burns (6.7\%). Regarding the degree of burn, most of cases $(60 \%)$ have got $2^{\text {nd }}$ and $3^{\text {rd }}$ degree burns, followed by $3^{\text {rd }}$ 
degree burns in $(20 \%)$ of cases. The total body surface area (TBSA\%) affected in most of the patients $(51.6 \%)$ was $(20-25 \%)$, while many patients $(43.3 \%)$ showed TBSA\% of burn $(25-50 \%)$. Most of the burned patients $(55 \%)$ had improved, $31.7 \%$ deteriorated, and $13.3 \%$ died during the study.

In table 2 and Fig (1-5), the study revealed that there was a significant increase in blood urea and serum creatinine mean values in burned patients, compared to healthy control specially during the third and the fifth days post burn. The random blood glucose (RBG) level showed significant difference where they showed maximum increase during the first day post burn compared to control, while the $3^{\text {rd }}$ and $5^{\text {th }}$ days post burn showed less significant increase in comparison to control level. Regarding serum electrolytes, the serum $\mathrm{Na}+\& \mathrm{~K}^{+}$levels declined in a significant manner during the $3^{\text {rd }}$ and $5^{\text {th }}$ days post burn, while its level did not show any significant differences during the $1^{\text {st }}$ day post burn.

Table 3 and fig (6-11), show a significant increase in (WBCs) and Neutrophils count during the $1^{\text {st }}, 3^{\text {rd }}$ and $5^{\text {th }}$ days post burn compared to the control group, where the highest increase was noticed during the $1^{\text {st }}$ day post burn. The Platelets count showed significant decrease in burn patients throughout the whole period of monitoring with the great lowering was in the $3^{\text {rd }}$ day. Hemoglobin $(\mathrm{Hb})$ level showed no significant difference during the $1^{\text {st }}$ day whereas it showed significant decrease during the $3^{\text {rd }}$ and $5^{\text {th }}$ days post burn. Red blood cells (RBCs) count increased in a significant manner during the $1^{\text {st }}$ day, then decreased significantly on the $5^{\text {th }}$ day post burn. The hematocrit value (HCT) decreased significantly on the $3^{\text {rd }}$ and $5^{\text {th }}$ days post burn.

Table 4 and fig (12-19) show the mean values of the liver functions, regarding liver transaminases (ALT \& AST) and alkaline phosphatase (ALP) the mean values showed significant increase after burn specially on the $5^{\text {th }}$ day. The serum levels of total protein and albumin decreased in a significant manner during the whole days post burn under the study. Regarding the coagulation profile, the prothrombin concentration (PC) was lowered and Prothrombin time (PT) was prolonged in a significant manner in burn patients during the whole period of the study. The International Normalized Ratio (INR) showed a significant increase in patients over the control value on the $1^{\text {st }}, 3^{\text {rd }}$ and $5^{\text {th }}$ days post burn.

Table (1): Burn characteristics of the studied patients

\begin{tabular}{|l|c|c|}
\hline Burn characteristics & No. $(\mathrm{n}=60)$ & 76.7 \\
\hline Cause of burn: & & 16.6 \\
\hline Flame & 46 & 6.7 \\
\hline Hot liquid & 4 & 76.7 \\
\hline Electric current & & 16.6 \\
\hline Type of burn: & 46 & 6.7 \\
\hline Dry & 10 & 13.3 \\
\hline Scald & 4 & 6.7 \\
\hline Electric & & 60.0 \\
\hline Degree of Burn: & 8 & 20.0 \\
\hline First and Second & 4 & \\
\hline Second & 36 & 51.6 \\
\hline Second and Third & 12 & 43.3 \\
\hline Third & & 5.1 \\
\hline TBSA\%: & 31 & \\
\hline$<25 \%$ & 26 & \\
\hline $25-50 \%$ & 3 & 31.7 \\
\hline $50-75 \%$ & & \\
\hline Mean \pm SD & & \\
\hline Outcome of injury: & 33 & \\
\hline Improved & 19 & \\
\hline Deteriorated & 8 & \\
\hline Dead & & \\
\hline
\end{tabular}


Table (2): comparison between blood urea, serum creatinine, RBG, sodium and potassium levels in burn patients and control

\begin{tabular}{|c|c|c|c|c|c|c|c|}
\hline & $\begin{array}{c}\text { Burn (A) } \\
\mathrm{N}=60\end{array}$ & Burn (B) & Burn (C) & $\begin{array}{c}\text { Control } \\
\mathrm{N}=20\end{array}$ & \multirow{2}{*}{$\begin{array}{c}\text { P- } \\
\text { value }^{1}\end{array}$} & \multirow{2}{*}{$\begin{array}{c}\mathrm{P}- \\
\text { value }^{2}\end{array}$} & \multirow{2}{*}{$\begin{array}{c}\text { P- } \\
\text { value }^{3}\end{array}$} \\
\hline & Mean \pm SD & Mean \pm SD & Mean \pm SD & Mean \pm SD & & & \\
\hline Urea $(\mathrm{mg} / \mathrm{dl})$ & $40.15 \pm 22.32$ & $45.37 \pm 52.43$ & $53.29 \pm 24.57$ & $25.71 \pm 6.45$ & $0.017 *$ & $0.004 *$ & $0.001 *$ \\
\hline Creatinine $(\mathrm{mg} / \mathrm{dl})$ & $0.88 \pm 0.26$ & $0.97 \pm 0.42$ & $1.26 \pm 0.39$ & $0.77 \pm 0.26$ & 0.134 & $0.05^{*}$ & $0.01 *$ \\
\hline $\mathrm{RBG}(\mathrm{mg} / \mathrm{dl})$ & $151.39 \pm 58.40$ & $138.54 \pm 45.66$ & $146.84 \pm 61.73$ & $110.54 \pm 12.29$ & $0.003 *$ & $0.003 *$ & $0.043^{*}$ \\
\hline $\mathrm{Na}+(\mathrm{mmol} / \mathrm{L})$ & $138.96 \pm 4.53$ & $136.23 \pm 3.27$ & $134.40 \pm 4.69$ & $141.80 \pm 4.08$ & 0.064 & $0.000 *$ & $0.000 *$ \\
\hline $\mathrm{K}+(\mathrm{mmol} / \mathrm{L})$ & $4.37 \pm 0.53$ & $3.75 \pm 0.49$ & $3.69 \pm 0.41$ & $4.13 \pm 0.36$ & 0.091 & $0.03 *$ & $0.01 *$ \\
\hline
\end{tabular}

RBG (random blood glucose) $\mathrm{Na}$ (sodium)

Student $-t$ test where $\mathrm{P}<0.05=$ significant value

$\mathrm{K}$ (potassium) $\mathrm{N}=$ number of cases

p 2=comparison between control \& Burn (B), p 3=comparison between control \& Burn (C)

Table (3): complete blood picture parameters in burn patients compared to control

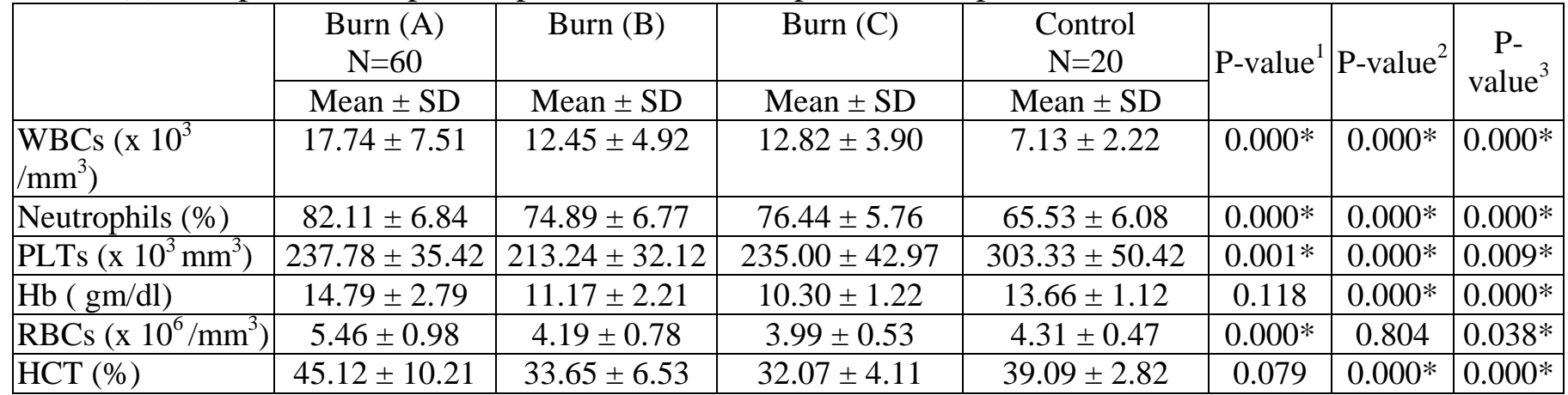

WBCs (white blood cells) - PLTs (platelets) - Hb (hemoglobin) - RBCs (red blood cells) - HCT

(hematocrit value) $\quad \mathrm{N}=$ number of cases

p $1=$ comparison between control \& Burn (A)

$3=$ comparison between control \& Burn $(\mathrm{C})$
Student $t$ test where $\mathrm{P}<0.05=$ significant value p 2=comparison between control \& Burn (B), p

Table (4): comparison between liver functions in burn patients and control

\begin{tabular}{|l|c|c|c|c|c|c|c|}
\hline & $\begin{array}{c}\text { Burn (A) } \\
\text { N=60 }\end{array}$ & Burn (B) & Burn (C) & $\begin{array}{c}\text { Control } \\
\text { N=20 }\end{array}$ & \multirow{2}{*}{ P-value $^{1}$} & P-value & P-value \\
\cline { 2 - 7 } & Mean \pm SD & Mean \pm SD & Mean \pm SD & Mean \pm SD & & & \\
\hline ALT (IU/L) & $29.71 \pm 14.38$ & $38.78 \pm 22.22$ & $49.36 \pm 20.16$ & $22.80 \pm 5.35$ & $0.021^{*}$ & $0.013^{*}$ & $0.000^{*}$ \\
\hline AST (IU/L) & $33.05 \pm 10.84$ & $34.13 \pm 14.87$ & $41.71 \pm 15.02$ & $25.47 \pm 3.29$ & $0.014^{*}$ & $0.013^{*}$ & $0.000^{*}$ \\
\hline ALP (IU/L) & $67.93 \pm 13.65$ & $74.53 \pm 13.70$ & $85.67 \pm 15.09$ & $55.07 \pm 11.00$ & $0.04^{*}$ & $0.015^{*}$ & $0.001^{*}$ \\
\hline Total protein (g/dl) & $4.76 \pm 0.70$ & $4.46 \pm 0.60$ & $4.53 \pm 0.84$ & $7.12 \pm 0.45$ & $0.007^{*}$ & $0.000^{*}$ & $0.000^{*}$ \\
\hline Albumin (g/dl) & $2.60 \pm 0.45$ & $2.41 \pm 0.40$ & $2.25 \pm 0.52$ & $3.83 \pm 0.41$ & $0.005^{*}$ & $0.000^{*}$ & $0.000^{*}$ \\
\hline PC $(\%)$ & $82.91 \pm 8.82$ & $76.09 \pm 9.28$ & $76.02 \pm 9.32$ & $99.13 \pm 1.13$ & $0.03^{*}$ & $0.000^{*}$ & $0.000^{*}$ \\
\hline PT (Sec) & $13.93 \pm 1.03$ & $14.59 \pm 1.16$ & $14.76 \pm 1.12$ & $12.05 \pm 0.07$ & $0.000^{*}$ & $0.000^{*}$ & $0.000^{*}$ \\
\hline INR & $1.14 \pm 0.09$ & $1.20 \pm 0.10$ & $1.23 \pm 0.10$ & $1.02 \pm 0.03$ & $0.04^{*}$ & $0.01^{*}$ & $0.001^{*}$ \\
\hline
\end{tabular}

ALT (alanine transaminase); AST (aspartate transaminase); $\quad$ ALP (alkaline phosphatase)

PC (prothrombin concentration); $\quad$ PT (prothrombin time); $\quad$ INR (international normalized

ratio); $\quad \mathrm{N}$ (number of cases) Student- $t$ test where $\mathrm{P}<0.05=$ significant value $\quad$ p 1=comparison between control \& Burn (A), p 2=comparison between control \& Burn (B), p 3=comparison between control \& Burn (C) 


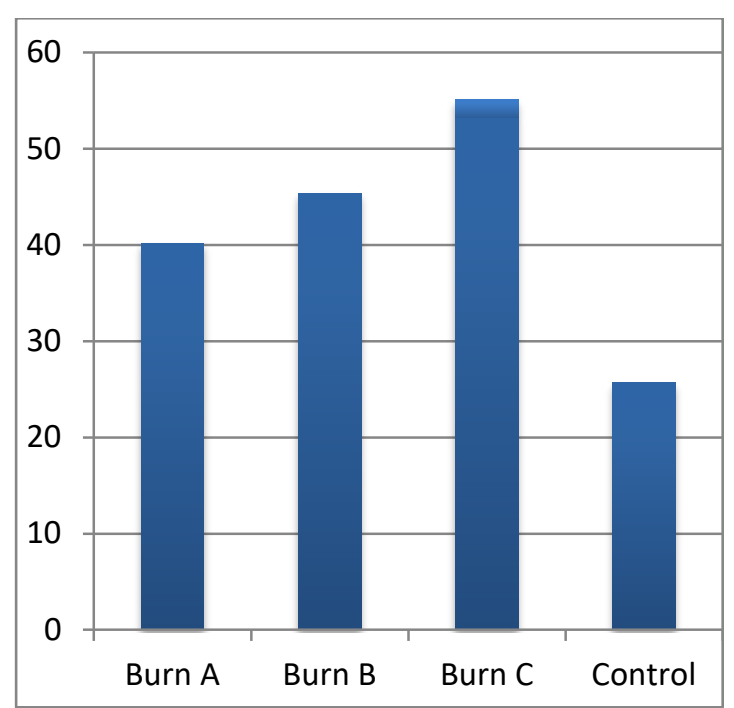

Figure (1): Blood urea level (mg/dl) in burn patients in comparison to control

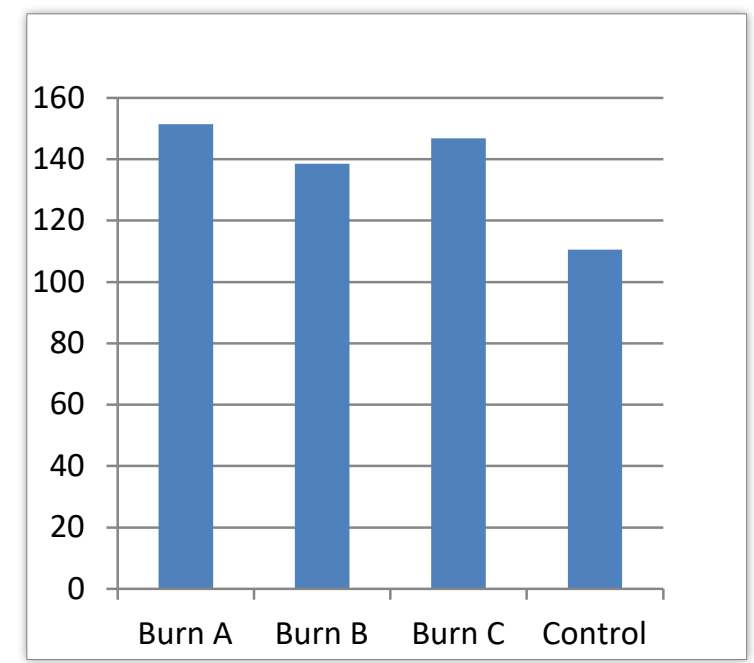

Figure (3): RBG mean level (mg/dl) in burn patients in comparison to control

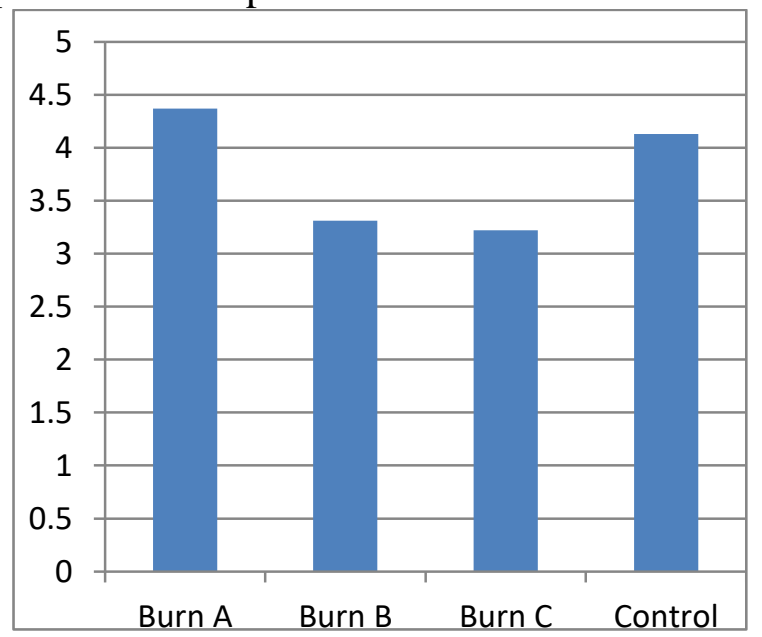

Figure (5): Serum $\mathrm{K}^{+}$mean level ( $\left.\mathrm{mmol} / \mathrm{L}\right)$ in burn patients in comparison to control

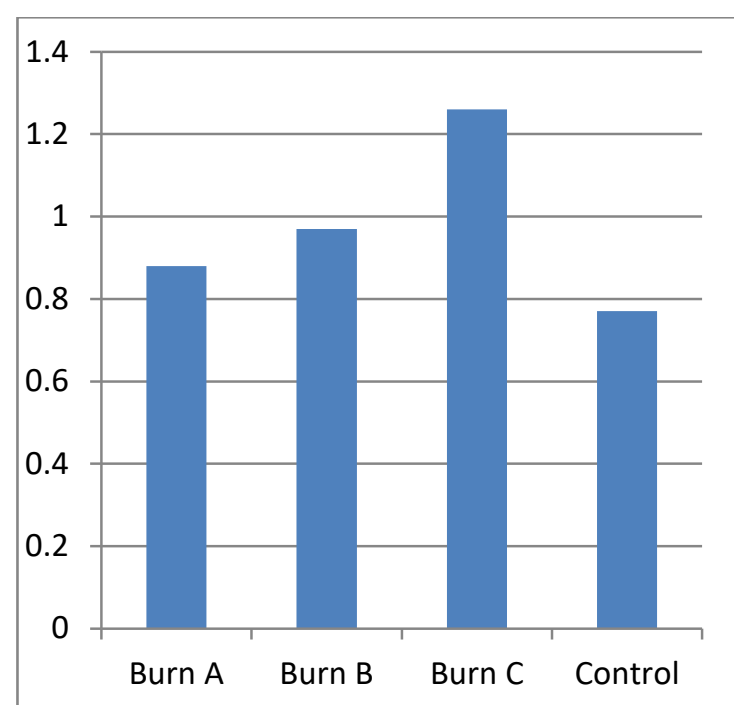

Figure (2): Serum creatinine level (mg/dl) in burn patients in comparison to control

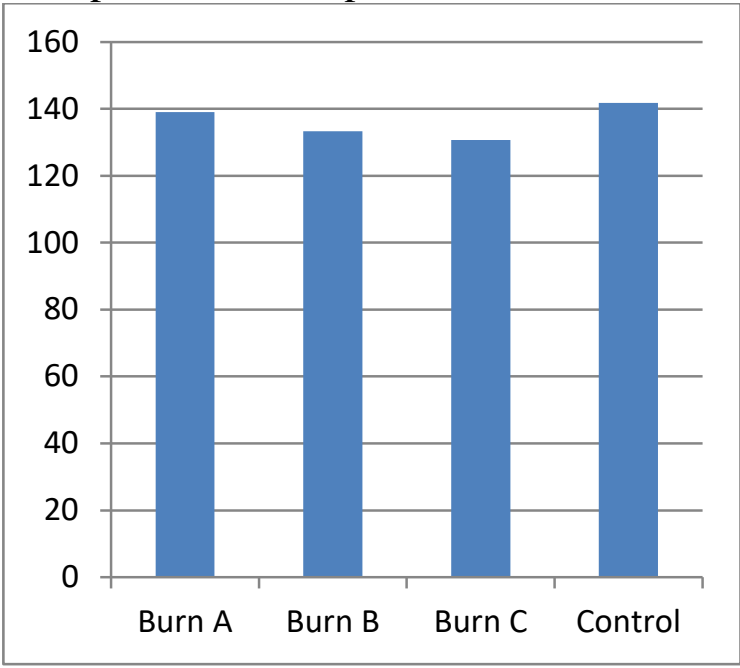

Figure (4): Serum $\mathrm{Na}^{+}$mean level ( $\mathrm{mmol} / \mathrm{L}$ ) in burn patients in comparison to control

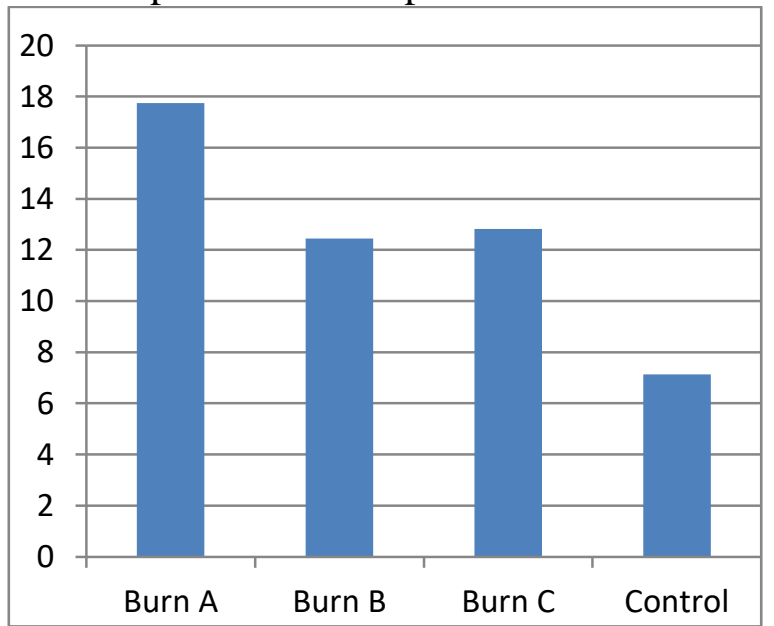

Figure (6):WBCs mean level $\left(\times 10^{3} / \mathrm{mm}^{3}\right)$ in burn patients in comparison to control 


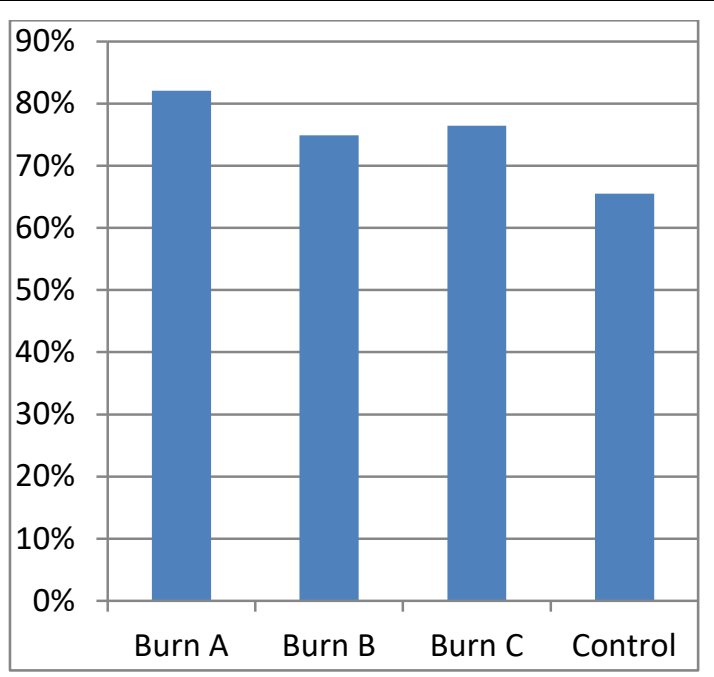

Figure (7): Neutrophils (\%) mean level in burn patients in comparison to control

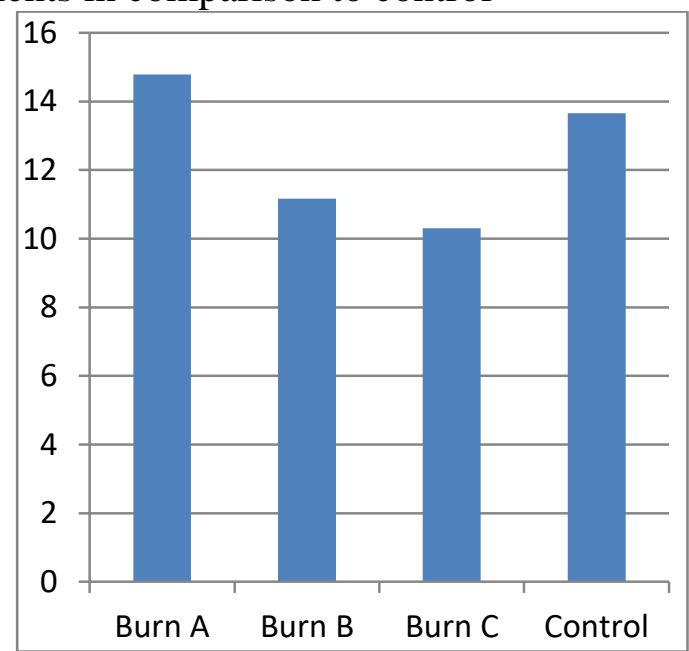

Figure (9): $\mathrm{Hb}$ mean levels in burn patients in comparison to control

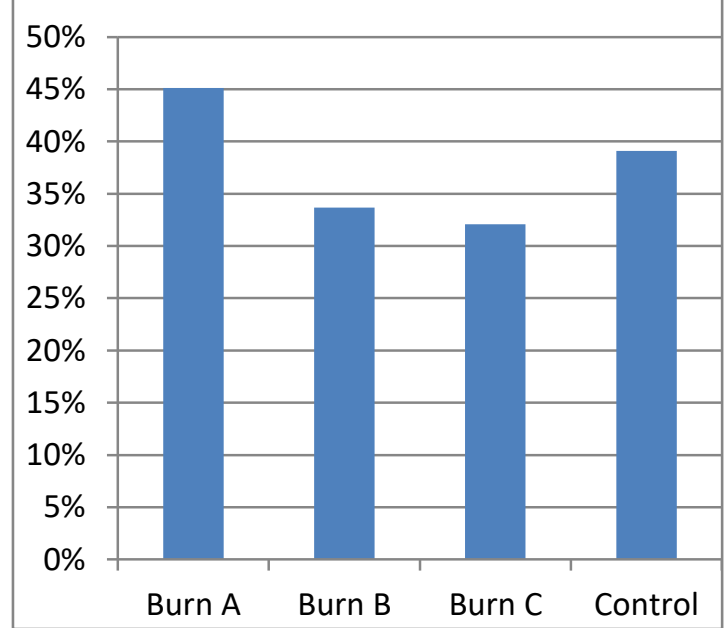

Figure (11): HCT mean levels in burn patients in comparison to control

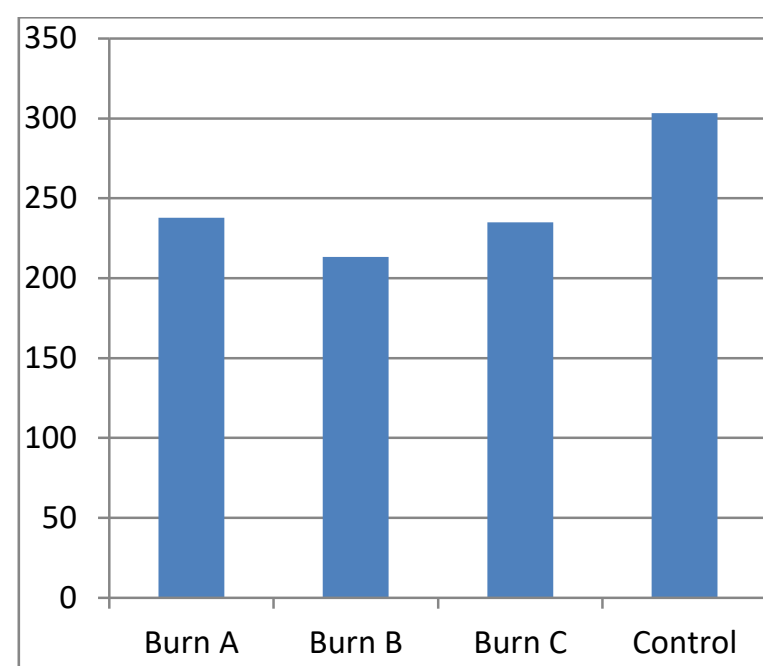

Figure (8): Platelet count mean level in burn patients in comparison to control

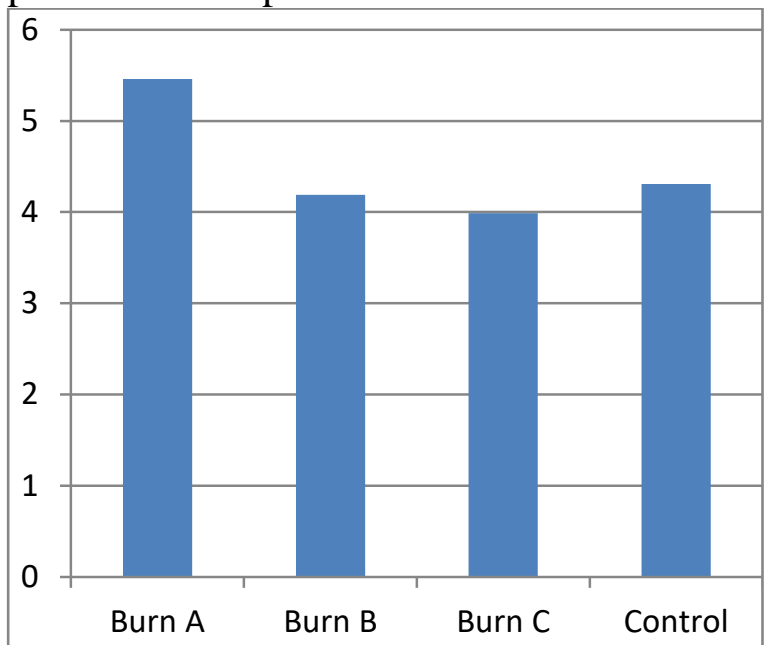

Figure (10): RBCs mean levels in burn patients in comparison to control

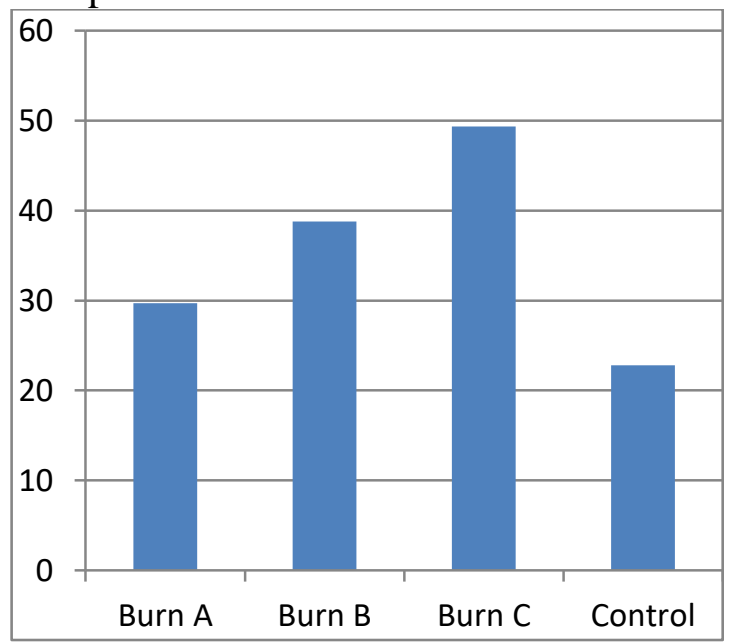

Figure (12): ALT mean levels in burn patients in comparison to control 


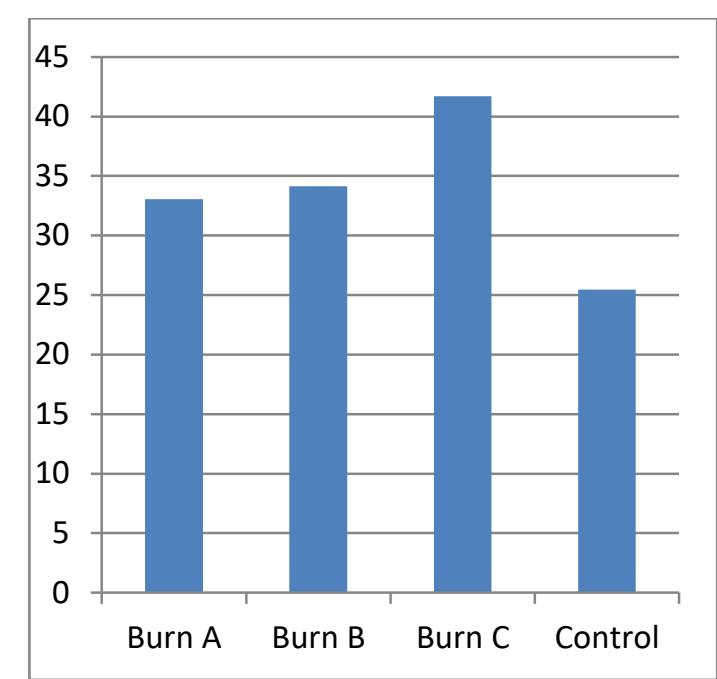

Figure (13): AST mean level in burn patients in comparison to control

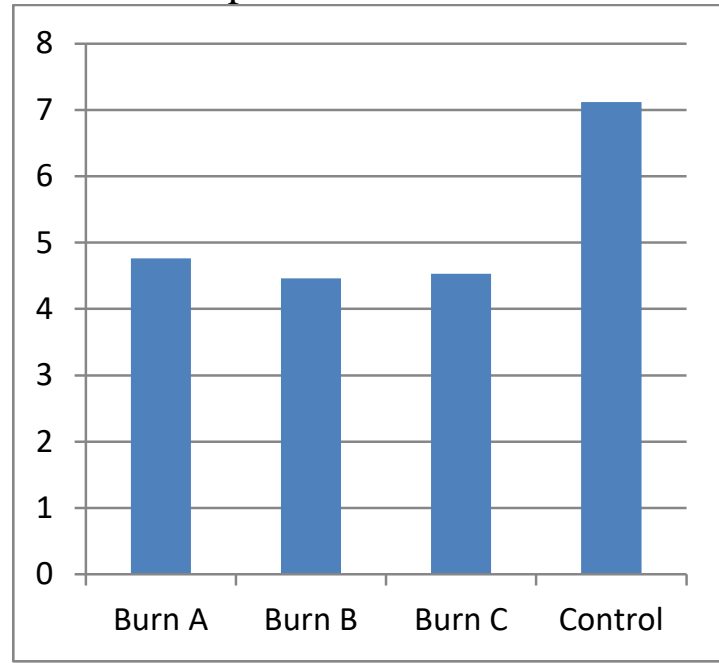

Figure (15): total Protein mean level in burn patients in comparison to control

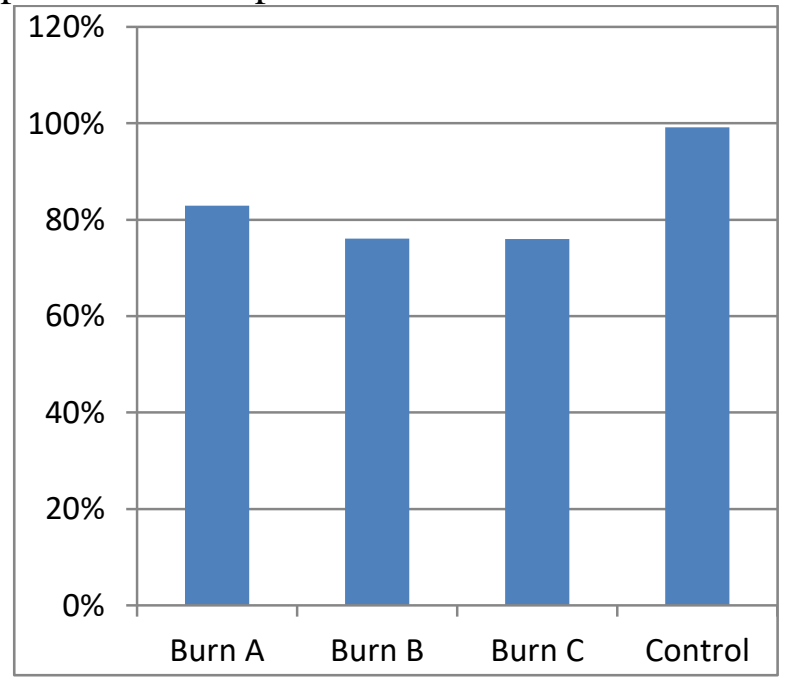

Figure (17): Prothrombin Concentration mean level in burn patients in comparison to control

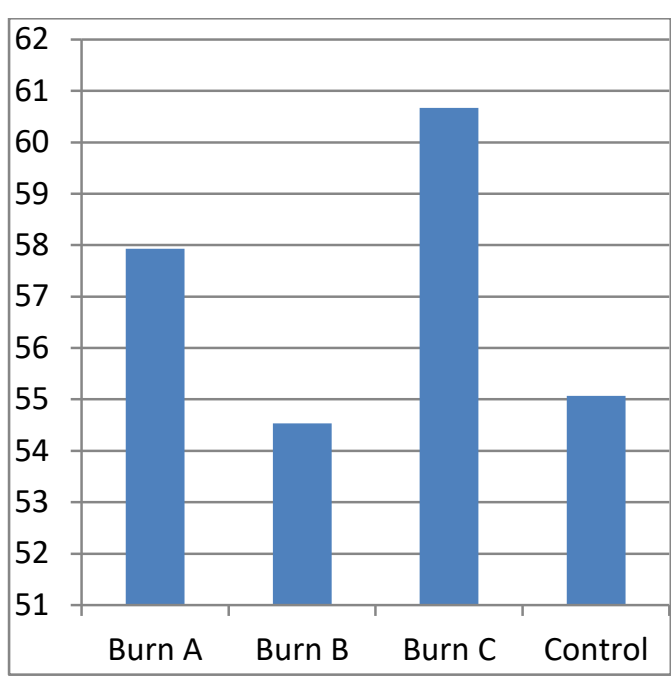

Figure (14): ALP mean level in burn patients in comparison to control

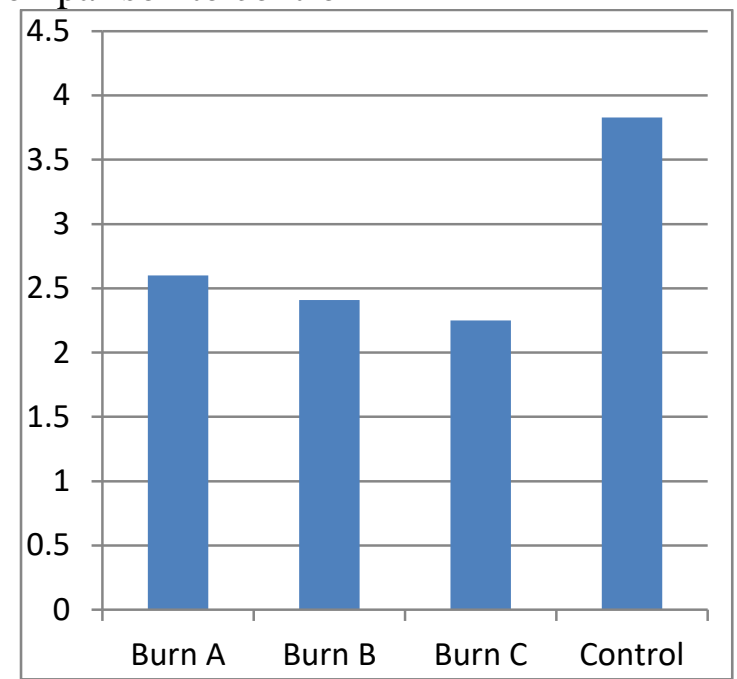

Figure (16): Serum Albumin mean level in burn patients in comparison to control

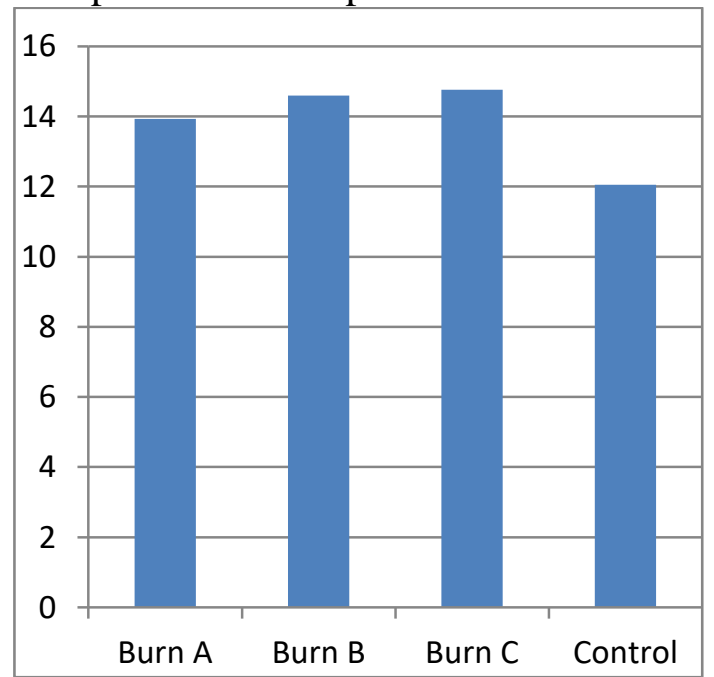

Figure (18): Prothrombin Time mean level in burn patients in comparison to control 


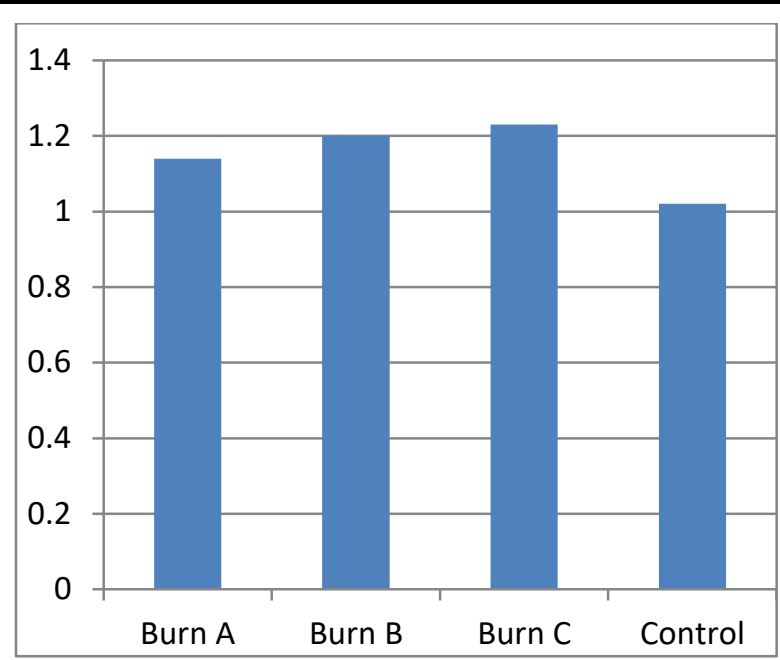

Figure (19): INR mean level in burn patients in comparison to control

\section{DISCUSSION}

The current study showed burn characteristics including cause, type, degree, (TBSA\%) affected and the outcome of the burn injury. concerning the cause and type of burn, we found that direct flame represents $76.7 \%$ of patients while scalds were $16.6 \%$ and the least common cause was the electrical burn accounting for $6.7 \%$. This result is in line with Kalayi (2006) and Dongo et al. (2007) who reported that dry burns assumed prominence over scalds. In a study conducted at PIMS Hospital, Islamabad, Pakistan the most common method of burn injuries was found to be flame burns followed by electrical, hot liquid, and chemical burns (Iqbal et al., 2005). However, a study was done for accidental burns, in Ardabil- Iran, found that $75 \%$ of burns were scalds, while $16 \%$ were caused by flames (Arshi et al., 2006). This contradiction may be due to demographical and socio-economical differences.

Comparing the different depths of burn, in this study, we found that combined second and third degrees burn represent $60 \%$, third-degree burn was $20 \%$, first and second degrees burn represent $13.3 \%$, isolated second-degree burn was $6.7 \%$. Our finding are in controversy with Fernandes et al. (2012) who reported that the second degree burns are the most predominant (62.6\%) of the cases surveyed, followed by combined second- and third-degree burns (13.4\%). One of the most important risk factors for mortality is the (TBSA), in our study the mean percent of TBSA was $35.87 \%$. Agbenorku et al. (2013) reported a similar result in their study where the highest mean \% TBSA was $35.07 \%$.

Regarding the outcome after the burn injury, $55 \%$ of the patients improved, $31.7 \%$ deteriorated and $13.3 \%$ died. By scoring individuals using the Abbreviated Burn Severity Index (ABSI) we can predict mortality for each patient according to certain variables which influence mortality. In our study most of the deaths due to burn injuries scored 8 and more by ABSI count. A study was done by Dahal et al. (2015) showed that ABSI count more than 6 has shown the higher mortality.

The most vulnerable organs in burn injuries are liver, kidney and pancreas, where their markers help in assessment of burn severity. Thermal injuries cause liver damage by different mechanisms including hypoperfusion, pro-inflammatory cytokines, cellular edema, and fatty changes) (Adiga and Adiga, 2015).

As regard the blood urea mean value in the present study, there was a significant increase from the first day after burn and rise more on the third and fifth days post burn, however the mean value of serum creatinine started to increase significantly from the $3^{\text {rd }}$ day after burn, and rise more on the $5^{\text {th }}$ day. In comparison to the above results, Anandani (2010) reported a significant rise in blood urea and serum creatinine levels started from the first day post burn and increased more on the $3^{\text {rd }}$ and $5^{\text {th }}$ days after burn. Two 
mechanisms of renal failure have been described in burn patients. The first one occurs early after the injury and is due to hypovolemia, low cardiac output, and systemic vasoconstriction, and the second one is the presence of some degree of myoglobinuria which can destroy tubular cells (Schneider et al., 2012).

In the present study, there was a significant increase in the mean random serum glucose level early on the first day post burn. This could be explained by stress due to severe pain $\&$ anxiety in many cases of burn, where the body respond by excessive secretion of glucagon, growth hormone, catecholamine, and glucocorticoid (Marti and Leitman, 2013).

The present study showed a significant decrease in serum $\mathrm{Na}^{+}$level on the 3rd and 5th days post burn while its level showed non-significant decrease on the 1st day post burn. In contrary to our findings, Kaddoura et al. (2003), Al-Muhammadi and Azeez, (2011) reported that a significant hyponatremia started in the first day of burn before starting resuscitation therapy and increased after resuscitation. A retrospective study done by Stewart et al. (2013) revealed that hyponatremia occurred in $6.8 \%$ and hypernatremia in $9.9 \%$ of burn patients.

In the present study, serum $\mathrm{K}^{+}$mean value showed non significant increase during the 1 st day post burn however, it showed a significant decline on the 3rd and 5th days post burn. This result is in agreement with Rainer et al. (1999), who reported that hypokalaemia is well recognized after stress conditions due to the combined effect of adrenaline and insulin, which stimulates receptors on skeletal muscle fibers with subsequent uptake of potassium from the circulation. The hypokalemia in the early post-resuscitation period between 2-5 days of burns' patients may be due to increased potassium losses (urinary, gastric or fecal). In disagreement with our findings, Kaddoura et al. (2017), Al-Muhammadi and Azeez (2011) reported that significant hyperkalemia occurred early in burn patients prior to resuscitation therapy.

The White Blood Cells count and the ratio of neutrophilic count showed a significant increase during the $1^{\text {st }}, 3^{\text {rd }}$ and $5^{\text {th }}$ days post burn where the maximum increase was recorded on the $1^{\text {st }}$ day post burn. Our results are similar to those of El-Sonbaty and El Otiefy (1996) who reported significant leukocytosis from the first day after burn, also the results of the present study are in line with Kim et al. (2011) and Belba et al. (2015) who reported that thermal injuries stimulate changes in hematopoiesis by inducing early acute phase response, and the WBC count is important hallmark in the evaluation of burn injuries. Our findings disagree with those of Barati et al. (2008) who reported that no significant differences were found in the total WBC count, in burn patients with or without bacterial infection. This controversy may be explained by the fact that the inflammatory systemic signs (changes in body temperature, tachycardia and leukocytosis) are used for diagnosis of sepsis, but sometimes this may be misleading, because critically ill burn patients often manifest a systemic inflammatory response syndrome without infection (Mokline et al., 2015).

Platelets count monitored in the present study showed a significant decline throughout the period of monitoring, this result is in line with Pavic and Milevoj (2007) who reported a significant decrease in platelets count which was observed in patients with moderate and severe burn injuries. A retrospective study done by Kim et al. (2011) on 265 burned patients showed that the platelet count started to increase immediately after thermal injury reaching the peak within 12 hours, then decreased gradually. Sarda et al. (2005) concluded that platelet count decreases initially in all cases of burn sepsis, then it gradually rises to normal in improving patients and declines gradually in deteriorating patients. The decrease in platelet count is caused by multiple factors, increased Platelet destruction, hemodilution and reduced platelet production (Pavic and Milevoj, 2007).

Regarding (RBCs) count, it increased in a significant manner during the $1^{\text {st }}$ day post burn, then decreased significantly on the $5^{\text {th }}$ day post burn. Hemoglobin (Hb) and (HCT) levels showed a significant decrease during the $3^{\text {rd }}$ and $5^{\text {th }}$ days post burn. This study 
agrees with Al-Muhammadi and Azeez (2011), EI-Sonbaty and EI-Otiefy (1996), who stated that (RBCs) count, hemoglobin concentration and hematocrit value showed significantly high levels immediately after burn, then decreased gradually to below the control level on the $4^{\text {th }}$ day post-burn. The decline of hematocrit value could be expected due to adequate fluid resuscitation, but may also be a sign of occult bleeding. Anemia which complicate severe burn injuries, usually starts few days after burn due to morphological changes in (RBCs) leading to increased destruction, and also due to decreased erythropoietin production and frequent surgical maneuvers done to those patients (Posluszny and Gamelli (2010). AlMuhammadi and Azeez (2011) found that hematocrit value decreased when major blood loss treated by plasma volume replacement or due to pre-existing anemia or hypervolemia.

Regarding serum levels of liver enzymes, the present study showed a highly significant increase in ALT, AST and ALP levels in burn patients, with the highest recordings on the $5^{\text {th }}$ day post burn. In agreement with our findings, Bhagwat et al. (2007) and Jeschke et al. (2007) reported elevation of liver enzymes in burn patients which reach maximum level by day 5. The excess release of hepatic enzymes could be explained by that burns lead to increase in edema formation that leads to cell damage (Adiga and Adiga, 2015).

The findings of the present study revealed significantly lower serum total proteins and serum albumin levels from the $1^{\text {st }}$ up to the $5^{\text {th }}$ days post burn in comparison with healthy control, also there were significant decrease in prothrombin concentrations and significant increase in prothrombin time and INR. These results were in accordance with AlMuhammadi and Azeez (2011), AguayoBecerra et al. (2013) and Deepthi et al. (2015). The mechanism of lowered values of serum proteins in the acute phase is due to local inflammatory cytokines which enter circulation in case of moderate and severe burn injuries resulting in systemic inflammatory response leading to generalized micro-vascular leak and permitting fluid \& protein loss from intra-vascular to extra- vascular compartments (Al-Muhammadi and Azeez, 2011). After the initial phase, hypoproteinemia and hypo-albuminemia persist because of the lack of their synthesis, loss through damaged skin areas, and lack of nutritional support (Kumar, 2010). The decreased prothrombin concentration and the increase in prothrombin time and INR represent one of the liver synthetic function which affected by burn injury

\section{CONCLUSION}

Mild and moderate burn injuries result in renal and hepatic dysfunction, in addition to disturbances in hematological parameters and bleeding profiles, so that estimation of hematological and serum biochemical markers in burn patients is very important for helping the health care team to expect the prognosis in burn patients and how the body is responding to the different therapeutic lines.

\section{RECOMMENDATIONS}

careful monitoring of liver and kidney functions, serum electrolytes and complete blood picture is very important in patients with moderate and severe burn injuries to prevent complications and improve outcome. We recommend follow up for longer period (4 weeks) in patients with altered biochemical parameters.

\section{REFERENCES}

-Adiga U and Adiga S (2015): Biochemical Changes in Burns. International Journal of Research Studies in Biosciences; 3 (7):8891.

-Agbenorku P, Agbenorku M and FiifiYankson PK (2013): Pediatric burns mortality risk factors in a developing country's tertiary burns intensive care unit. International Journal Burns Trauma.; 3(3):151-8.

-Aguayo-Becerra OA, Torres-Garibay C, Maci'as-Amezcua MD et al. (2013): Serum albumin level as a risk factor for mortality in burn patients. Clinics. 68(7):940-45.

-Al-Muhammadi MO and Azeez HA (2011): Some Physiological Changes in Burn Patients. Medical Journal of Babylon; 8(3): 303-19.

-Anandani JH (2010): Impact of thermal injury on hematological and biochemical 
parameters in burn patients. Biosci. Biotech Res. Comm; 3 (1): 97-100.

-Arshi S, Sadeghi-Bazargani H, Mohammadi $R$ et al. (2006): Prevention oriented epidemiologic study of accidental burns in rural areas of Ardabil, Iran. Burns, 32(3):366-71.

-Barati M, Alinejad F, Bahar MA et al. (2008): Comparison of WBC, ESR, CRP and PCT serum levels in septic and nonseptic burn cases. Burns, 34(6): 770-74.

-Belba M, Aleksi A, Nezha I et al. (2015): Impact of Severe Burns in Hematological Parameters. AJMHS, 46 (3): 59-69

-Bhagwat VR, Subrahmanyam M and Pujari KN (2007): Serum enzymes in thermal injury. Indian Journal. Clinical Biochemistry. 22 (2): 154-57.

-Cakir B and Yegen BC (2004): Systemic responses to burn injury. Turk Journal Med Sci. (34): 215-26.

-Dahal P, Ghimire S, Maharjan NK et al. (2015): Baux's and Abbreviated Burn Severity Score for the Prediction of Mortality in Patients with Acute Burn Injury. Journal of College of Medical Sciences-Nepal, Vol-11, No 4, Oct-Dec 015. -Deepthi SKD and Narayan GAR (2015): Evaluation of serum albumin levels and its relation to burn size in burn patients. World journal of Pharmacy and Pharmaceutical Sciences 4(8): 1462-5.

- Dongo, AE, Irekpita, EE, Oseghale, LO et al. (2007): A five-year review of burn injuries in Irrua. BMC Health Serv Res.; 7:171.

-El-Sonbaty MA and El -Otiefy MA (1996): Hematological changes in severely Burned Patients . Annals of Burns and Fire Disasters 9(4): 1-4.

-Fernandes FMFA, Torquato IMB, Dantas MAS et al. (2012): Burn injuries in children and adolescents: clinical and epidemiological characterization. Rev Gaúcha Enferm. 33(4):133-41.

-Halkes S, van den Berg A, Hoekstra M (2002): Transaminase and alkaline phosphatase activity in serum of burn patients treated with highly purified tannic acid. Acta Chir Plast. 28: 449-53.

-Hettiaratchy S and Papini R (2004): Initial management of a major burn: II- assessment and resuscitation. BMJ. 329(7457): 101-3.

-Iqbal T, Rashid R and Ibrahim M (2005): Incidence of burn injury admission at PIMS, Islamabad. Ann Pak Inst Med Sci. 1:194-5.

-Jeschke MG, Micak RP, Finnerty CC et al. (2007): Changes in liver function and size after a severe thermal injury. Shock 28:1727.

-Kaddoura I, Sittah GA, Karamanoukian R et al. (2017): Burn injury: review of pathophysiology and therapeutic modalities in major burns. Ann Burns Fire Disasters. Jun 30; 30(2): 95-102

-Kalayi GD (2006): Mortality from burns in Zaria: an experience in a developing economy. East Afr Med Journal 83: 461-64.

-Kim HS, Kwon HW, Yang HT et al. (2011): A Serial Study of Hematologic Change in Burned Patients. Journal Lab Med Qual Assur. Jun; 33(1): 9-16.

-Kim GH, Oh KH and Yoon JW (2003): Impact of burn size and initial serum albumin level on acute renal failure occurring in major burn. Am Journal Nephrol 23: 55-60.

-Kumar P (2010): Grading of severity of the condition in burn patients by serum protein and albumin/globulin studies. Ann Plast Surg.; 65(1):74-9.

- Lavrentieva A, Depetris N and Kaimakamis E (2016): Monitoring and treatment of coagulation abnormalities in burn patients. An international survey on current practices. Ann Burns Fire Disasters. 29: 172-77.

-Mahmood S, Prabhakar M, Anees S et al. (2016): Hypoproteinemia, Hypocalcemia, Hyponatraemia, Hyperkalaemia and Trace Elements in Patients with Burn Injuries. International journal of scientific research 5(10): 588-9.

-Marti JL and Leitman IM (2013): Understanding the causes of hyperglycemia in burn patients. Journal of surgical research 182. 205-6.

-Mokline A, Garsallah L, Rahmani I et al. (2015): Procalcitonin: a diagnostic and prognostic biomarker of sepsis in burned patients. Ann Burns Fire Disasters. Jun 30; 28 (2): 116-20 
-Pavic M and Milevoj L (2007): Platelet count monitoring in burn patients. Biochemia Medica 17(2): 212-19.

-Peck M and Pressman MA (2013): The correlation between burn mortality rates from fire and flame and economic status of countries. Burns 39:1054.

-Pham TN, Cancio LC and Gibran NS (2008): American Burn Association practice guidelines: Burn shock resuscitation. Journal Burn Care Res 29(1): 257- 66.

--Posluszny JA and Gamelli RL (2010): Anemia of thermal injury: combined acute blood loss anemia and anemia of critical illness. Journal Burn Care Res. 31: 229-42.

-Rainer TH, Beattie T, Crofton P et al. (1999): Systemic hormonal, electrolyte, and substrate changes after non-thermal limb injury in children. Journal Accid. Emerg. Med. March; 16(2): 104-7.

-Sarda DK, Dagwade AM and Lohiya S (2005): Evauation of platelet count as a prognostic indicator in early detection of post burn septicaemia. Bombay Hosp Journal 47(3): 36.

-Schneider DF, Dobrowolsky A, Shakir IA et al. (2012): Predicting acute kidney injury among burn patients in the 21st century: a classification and regression tree analysis. Journal Burn Care Res. 33 (2):242-51.

-Stewart IJ, Morrow BD, Tilley MA et al. (2013): Dysnatremias and survival in adult burn patients: a retrospective analysis. Am Journal Nephrol. 37:59-64 